\title{
Cotidiano
}

\section{TRABALHANDO OS CONCEITOS DE AUTOCONHECIMENTO E AUTOCONSCIÊNCIA COM METODOLOGIA VIVENCIAL}

\author{
Gislene Farias de Oliveira (1) \\ Mônica Maria Siqueira Damasceno (2) \\ Francisco Wellery Gomes Bezerra(3) \\ Francisco Steferson da Silva (4)
}

\begin{abstract}
Resumo
O autoconhecimento e o desenvolvimento de habilidades inter-pessoais constitui um dos pressupostos que fundamentam a proposta dos currículos das Ciências Humanas, dentre as quais, as Ciências Sociais. O presente estudo aborda a aplicação de metodologia vivencial na área de ensino das Ciências Sociais, no desenvolvimento de habilidades como a empatia e o diálogo entre acadêmicos do referido curso. $\mathrm{O}$ estudo foi conduzido a partir do material coletado numa atividade vivencial proposta para os alunos da disciplina de Psicologia Social do $3^{\text {a }}$ semestre do curso de Ciências Sociais da universidade Regional do Cariri em Crato-CE. Nessa experiência, foram trabalhados os conceitos de autoconhecimento e autoconsciência através de técnicas de relaxamento, visualização e desenho. De início os alunos foram estimulados a um relaxamento leve, com a finalidade de facilitar a experiência de visualização. Em seguida, a entrarem em contato com experiências pessoais, onde sentiram-se fortalecidos em suas ações, decisões ou comportamentos. O passo seguinte foi a expressão de si mesmo através de um desenho e o compartilhar com os colegas das impressões de si mesmos eliciadas na experiência, através dos desenhos. Os resultados apareceram de forma contrastante, evocando tanto sentimentos positivos de possibilidade e segurança, como sentimentos negativos, experienciados na forma de incerteza. Concluímos pois, que a metodologia vivencial proporcionou aos estudantes um aprendizado em termos de autoconhecimento e conhecimento do outro, além do desenvolvimento de recursos internos para uma vida melhor.
\end{abstract}

Palavras-Chave: Metodologia; Vivência; Autoconhecimento 


\section{Introdução}

A saúde emocional dos profissionais parece ainda ser uma temática latente nos dias de hoje. Características como desrespeito, inabilidade no trato interpessoal, desconfiança, insegurança, tem sido habitualmente apontadas como fatores responsáveis ou desencadeantes de dificuldades emocionais.

O currículo do curso de Ciências Sociais, adotado pela Universidade Regional do Cariri - URCA, prevê o desenvolvimento de habilidades inter-pessoais como um dos seus pressupostos básicos. Neste sentido, a metodologia vivencial torna-se mais um instrumento para o desenvolvimento de habilidades como a empatia, solidariedade, comunicação e responsabilidade social entre estudantes de Ciências Sociais.

A vivência é o conhecimento adquirido no processo de vivenciar uma situação. Este é de extrema importância para uma conscientização dos nossos atos e comportamentos. Em geral, essa participação ativa, é promotora do crescimento humano, pois elicia uma percepção mais acurada de nós mesmos.

A metodologia vivencial é um método de aprendizado que se caracteriza por ser de experimentação ativa; possibilitador de reflexões e generalização por analogias; e de aplicação dos novos conteúdos aprendidos em outras situações.

A técnica da vivência, segundo Carvalho Neto e Melo (2004), consiste basicamente de quatro etapas: 1- Técnicas de relaxamento; 2- Contato com experiências pessoais relacionadas ao ato de cuidar; 3- Compartilhamento de experiências e 4- Expressão de sentimentos.

O aprendizado vivencial é muito mais eficaz na formação do aluno das Ciências Humanas porque suporta um envolvimento ativo no processo de aprendizado e permite ao indivíduo a internalização e memorização mais abrangente dos conceitos através da experiência direta. Não objetiva ensinar conceitos, habilidades e valores, mas sim oferecer oportunidades aos indivíduos de internalizar e abraçar idéias e ideais experimentados durante o processo vivencial (OLIVEIRA e CALLOU, 2006).

Em geral, a metodologia vivencial é agradável por envolver ativamente os alunos. As atividades são prazerosas e catalisadoras de aumento da motivação e participação, ambas características desejáveis aos profissionais que lidam com pessoas. (GIFFONI et. al., 2007).

Diferentes propostas de aula ou atividades inesperadas requerem o mais autêntico e imediato engajamento com as tarefas e as pessoas disponíveis. Dessa forma, as atividades 
vivenciais têm o potencial de aumentar os limites, pois trabalha em graus diferentes de incerteza e desconhecimento e como conseqüência, os indivíduos são movidos a lembrar, imaginar, experienciar e explorar novos caminhos de interação.

O uso dessa metodologia em sala de aula reforça positivamente a experiência de aprendizado, dando origem a um aprendizado mais significativo e duradouro, quanto mais vier a mobilizar a energia emotiva. Além disso, a metodologia vivencial tem sua justificativa em proporcionar uma constante e rápida mudança que é indispensável para desenvolver a capacidade dos alunos, em termos de: flexibilidade; auto-conhecimento, empatia; respeito; gerenciamento da mudança e da incerteza; trabalho de equipe para atingir objetivos comuns; perseverança; assunção de riscos calculados e necessidade de planejamento (OLIVEIRA E CALLOU, 2006).

Segundo carvalho Neto e Melo (2004), a metodologia vivencial deve ser utilizada nas situações em que esse instrumento didático tenha um claro objetivo de aprendizado. No caso, pode revelar-se particularmente eficaz em situações que reflitam confiança; liderança; organização grupal; competitividade; comunicação eficaz; clima colaborativo; análise e resolução de problema; suplantação de limites e trabalho em equipe.

Esta metodologia é particularmente indicada para a formação comportamental de grupos quando a cultura organizacional da qual se originam não é demasiadamente hierárquica. Nesse contexto a cumplicidade amigável no grupo, tem mais possibilidades de ser transferida pelo modelo cognitivo aprendido (CARVALHO NETO e MELO, 2004).

O presente estudo aborda a metodologia vivencial no desenvolvimento de habilidades inter-pessoais como auto-conhecimento, empatia e o diálogo entre estudantes de Ciências Sociais. Seu objetivo geral foi demonstrar a importância de se introduzir metodologias vivenciais no curso de Ciências Sociais e, para isso foi necessário: a) investigar a eficácia da metodologia vivencial na abordagem dos temas "autoconhecimento e autoconsciência" na disciplina de Psicologia Social da Universidade Regional do Cariri - URCA/CE e, b) despertar no aluno a importância da empatia e da solidariedade como habilidades interpessoais na prática profissional.

\section{Método}

O estudo foi organizado a partir do material coletado numa atividade vivencial proposta para 30 (trinta) alunos de ambos os sexos, da disciplina de Psicologia Social do $3^{\text {a }}$ 
semestre do curso de Ciências Sociais da universidade Regional do Cariri, no município de Crato-CE, no ano de 2008. Nessa experiência, foram trabalhados os conceitos de autoconhecimento e autoconsciência através de técnicas de relaxamento, visualização e desenho, em sala de aula.

\section{Procedimento}

De início os alunos foram estimulados a um relaxamento leve, com a finalidade de facilitar a experiência de visualização. Em seguida, a entrarem em contato com experiências pessoais, onde puderam relembrar experiências em que sentiram-se fortalecidos em suas ações, decisões ou comportamentos, em qualquer momento da sua vida. O passo seguinte foi a expressão de si mesmos através de um desenho em folhas de papel ofício.

Num terceiro momento, os alunos agruparam-se aos pares com a finalidade de compartilhar com os colegas as impressões de si mesmos eliciadas na experiência, através dos desenhos. Eles foram orientados a iniciarem o diálogo à partir do desenho, expressando suas percepções de si, iniciando com a seguinte frase: “Eu sou...”.

Ao final, foi solicitado aos participantes relatarem na própria folha do desenho, o que aprenderam com a experiência.

A seguir descreve-se os resultados dos relatos dos participantes.

\section{Resultados}

Com relação ao Reconhecimento de si, pelos participantes, a experiência parece ter eliciado duas categorias contrastantes: Uma Positiva, evocando sentimentos de Possibilidade e de Segurança para consigo mesmo. Neste caso, a visão de si denotou uma elevada autoestima dos participantes. E, uma Negativa, onde os alunos se perceberam como pessoas inseguras ante suas próprias possibilidades.

A seguir, apresenta-se as descrições das categorias evocadas na experiência.

Descrições das Categorias e Subcategorias das percepções experienciadas pelos participantes, a partir da representação de si mesmos (Como me reconheço?). 
A experiência fez emergir nos alunos duas categorias. Um grupo se reconheceu de maneira positiva, percebendo em si Possibilidade e Segurança. Outro grupo se reconheceu de uma forma mais negativa, evocando uma percepção de Incerteza, como pode ser observado pelas falas dos participantes, a seguir.

CATEGORIA 1 - POSITIVA, com duas sub-categorias:

a) Possibilidade. Neste caso, os alunos se reconheceram como um ser pleno de possibilidades. Essa subcategoria ficou demonstrada através das seguintes falas: "liberdade de buscar novas conquistas"; "novos horizontes"; "busca incessante”; " procurando um objetivo”; “caro, bolsa, cabe tudo”; "viver”; “ posso ser"; " conseguir"; " superação”; “ escada”; " busca constante de se superar"; "energia”; "água, sensibilidade e força”; "idéias”; “criatividade”; "sonhos"; "refletindo meu comportamento"; "infinito".

b) Segurança. Neste caso, suas Representações de si mesmos denotaram tranqüilidade e segurança. Observe-se suas falas: "harmonia” (4); “luz”(2); "segurança”; “ Calmaria”; " no final tudo deu certo”; “ a paz toma conta do espaço"; "família"(3); "trabalho”; “amigos fazem parte do meu dia-a-dia” (2); “ lugar calmo”; “paz”(2); “ eu amo a mim”; “ beleza”; “perfeito”; “ sou o que sou”; “ uma dualidade inteira”; "reflexão”; "alegria”(2); " ensinar”; "fé”; “ amizades"; "recordação"; "saudade”." "bíblia”.

CATEGORIA 2 - NEGATIVA, com uma sub-categoria:

a) Incerteza. Neste caso, os alunos se reconheceram como pessoas com limitação, dúvida e temor em relação a sua capacidade pessoal, frente a certas situações. Essa subcategoria ficou demonstrada através das seguintes falas: "sou dificil de ler"; "máscara”; "noite”; "dúvida”; "ameaça”; "carência”; "confusão”; "medo de seguir"; "lágrimas”; "minha brutalidade”; "posição de ataque”; "refletindo meu comportamento"; "sentada".

Com relação ao questionamento aos participantes sobre "O que aprendi com $\boldsymbol{a}$ vivência?", observou-se três categorias. Alguns participantes sentiram que a vivência 
promoveu uma maior consciência de si mesmos (Autoconhecimento), outros puderam experienciar uma maior empatia com os colegas (Conhecimento do outro), prestando mais atenção às suas motivações e formas de si perceberem e, outro grupo parece ter saído da experiência mais fortalecidos quanto a uma maior compreensão sobre a vida ( Conhecimento sobre a vida), como pode ser observado nas falas a seguir:

CATEGORIA 1 - Autoconhecimento: Neste caso, a vivência parece ter sido promotora de uma profunda reflexão sobre si mesmos.

"aprendi a olhar mais para mim”;

“aprendi sobre mim que sempre busco algo a mais”;

"sou uma pessoa fácil de se relacionar”;

"Possibilidade de nos conhecer melhor"

"Senti o quanto é bom pensar sobre nossas atitudes";

"é dificil se expor”;

"Ficamos preocupados em procurar melhores palavras, isso cria uma barreira";

“ aprendi a tentar me expressar mais";

“aprendi que...eu realmente não sou o que as pessoas pensam ao meu respeito”

"Aprendi a relaxar mesmo em ambiente com muita gente”;

“ meu reflexo não é da imagem que eu penso que reflito”;

“aprendi a me preocupar comigo mesma”;

"Existem pessoas parecidas comigo";

"que sou inconstante”;

“aprendi ame expressar através de outros meios que não as palavras";

"Me abrir mais, acreditar e confiar mais em mim”;

" tenho dificuldade para me expressar”;

"Aprendi que me preocupo demais com a opinião das pessoas";

"As aflições no meu passado se refletiram no desenho"

“ consegui superar uma fase confusa”;

"aprendi que a água expressa minha personalidade - suavidade, força, desejo de ver os outros bem e amor a liberdade”;

“Aprendi a compartilhar a auto-percepção e os sentimentos”; 
CATEGORIA 2- Conhecimento do outro: Neste caso, a vivência parece ter sido promotora de uma releitura sobre os pessoas, promotora de uma nova consciência a respeito da importância da assistência ao outro, principalmente no tocante ao cuidado e ao respeito para com as suas peculiaridades individuais.

"Aprendi que é bom ouvir o outro, pensar e relacionar opiniões"

"Aprendi a expor o que penso das outras pessoas";

" cuidado com as pessoas";

"respeitar as diferenças";

" respeitar as culturas e as individualidades";

"aprendi a amar as pessoas como se não houvesse amanhã"

"mesmo longe as pessoas têm influência na nossa vida";

"temos inúmeras oportunidades de conhecer pessoas mas deixamos passar essa chance todo dia".

CATEGORIA 3- Conhecimento sobre a vida: A vivência foi experienciada como um recurso pessoal que permite viver melhor.

"aprendi que temos que pensar e ver o que realmente queremos, ser mais objetivos";

"aprendi que devemos fazer tudo que temos vontade"

"o passado não volta e o futuro demora a chegar"

"Paciência é a melhor virtude dos homens";

“aprendi paciência e fé”,

"um ato de reflexão, nos remete a mansidão interna”;

“pensamento é um exercício difícil e complexo, mas tem efeito transformador”;

" uma pequena conversa pode nos ensinar algo que se leva para uma vida inteira”;

\section{Discussão}

Este estudo corrobora observações de Martins (1995) que afirma que, se os profissionais das ciências humanas tiverem uma mente aberta, não saturada por preconceitos, 
estarão diante de uma riqueza de conhecimentos imensa ao seu alcance. Daí a importância de uma metodologia, em cursos das ciências sociais, que promova o contato dos alunos com situações que suscitem reflexão acerca de seus sentimentos, atitudes e comportamentos.

Giffoni et. al. (2007), em estudo semelhante acerca das representações sociais sobre o uso de uma metodologia vivencial no tratamento de pessoas com dificuldades mentais e emocionais e seus familiares, concluiu que esta evocou nos participantes representações positivas acerca da metodologia, relacionadas ao Bem-estar, a Socialização e a Ressignificação, possibilitando um novo modo de pensar suas atitudes e comportamentos. A autora concluiu que a adoção de uma metodologia vivencial, ajudou os participantes a se reconhecerem como sujeitos ativos do seu processo de mudança.

Observa-se neste caso a semelhança relacionada às evocações positivas de Possibilidade e Segurança, onde a vivência parece ter sido promotora de uma nova consciência a respeito do seu autoconhecimento, do conhecimento do outro e de um melhor conhecimento sobre a vida.

Oliveira e Callou (2006), realizaram um estudo com 40 (quarenta) alunos do segundo semestre de medicina da Universidade Federal do Ceará - Barbalha em 2005, na disciplina de Psicologia do desenvolvimento, onde foi introduzida uma nova metodologia conhecida como Trabalho colaborativo, na educação médica. Esta modalidade de atividade permitiu aos participantes se auto-ajudarem no seu processo de aprendizagem, atuando como parceiros entre si, visando adquirir um determinado conhecimento. As autoras concluíram que este tipo de trabalho além de promover o acesso dos alunos a novas tecnologias aplicadas na educação médica, também proporcionou o desenvolvimento de habilidades inter-pessoais, necessárias a outras situações da vida pessoal e profissional.

\section{Conclusão}

A atividade proposta aos alunos exigiu dentre outras coisas: concentração; respeito aos colegas; gestão do tempo, empatia e descobrimento da capacidade de tolerância, que são utilizados para ensinarem os indivíduos a gerir problemas ou situações complexas, seja nas atividades cotidianas laborativas ou da vida.

A metodologia vivencial se mostrou útil no desenvolvimento pessoal dos alunos, por proporcionar um maior contato com sentimentos próprios e dos colegas, o que possibilitou uma maior conscientização de suas atitudes e percepção de si mesmos, promotores do 
autoconhecimento. Dessa forma acredita-se ter demonstrado a eficácia da utilização da metodologia vivencial na formação de alunos do curso de Ciências Sociais, que participaram do presente estudo.

\section{Referências}

CARVAlhO NETO, C. Z. \& MELO, M. T. E agora, professor? Por uma Pedagogia

Vivencial. IFCE - Instituto para a Formação Continuada em Educação (edição em Multimídia): São Paulo, 2004

GIFFONI, F.A.O.; OLIVEIRA, G.F.; BRANCO, L.C.C e NOGUEIRA, R.R. S. A Terapia comunitária como metodologia inovadora no tratamento do desconforto emocional.

Trabalho apresentado no V Forum Nacioanl de Metodologias Ativas de EnsinoAprendizagem. Londrina-PR. Agosto, 2007.

MARTINS, L.A.N. Saúde mental do médico e do estudante de medicina. Relatório apresentado na mesa redonda: Saúde mental do médico e do estudante de medicina”. IV Encontro Brasileiro de Interconsulta Psiquiátrica e psiquiatria de Hospital Geral. Belo Horizonte-MG. Setembro, 1995.

OLIVEIRA, G F.e CALLOU, D.T. A Introdução do Trabalho Colaborativo na Educação Médica. Trabalho apresentado no XXI Outubro Médico. Fortaleza-CE. Outubro, 2006

Sobre os autores:

(1) Gislene Farias de Oliveira é Psicóloga, Doutora em Psicologia Social e Professora da Universidade Federal do Ceará. E-mail: gislenefo@ hotmail.com

(1) Mônica Maria Siqueira Damasceno é Pedagoga e especialista em Psicologia Aplicada à Educação e Professora do Departamento de Educação da Universidade Regional do Cariri.

E-mail: siqueiramonica@hotmail.com.

(2) Francisco Wellery Gomes Bezerra é acadêmico de Ciências Sociais pela Universidade Regional do Cariri - Crato/CE. E-mail: nego_well_@ hotmail.com.

(3) Francisco Steferson da Silva é acadêmico de Ciências Sociais pela Universidade Regional do Cariri Crato/CE. E-mail: stefersonsilva@ hotmail.com. 